\title{
BMJ Open Time intervals experienced between first symptom recognition and pathologic diagnosis of breast cancer in Addis Ababa, Ethiopia: a cross-sectional study
}

\author{
Alem Gebremariam (D) , ${ }^{1,2}$ Adamu Addissie, ${ }^{2}$ Alemayehu Worku, ${ }^{2}$ \\ Mathewos Assefa, ${ }^{3}$ Lydia E Pace, ${ }^{4}$ Eva Johanna Kantelhardt (1) , ${ }^{5}$ Ahmedin Jemal ${ }^{6}$
}

To cite: Gebremariam A, Addissie A, Worku A, et al. Time intervals experienced between first symptom recognition and pathologic diagnosis of breast cancer in Addis Ababa, Ethiopia: a crosssectional study. BMJ Open 2019;9:e032228. doi:10.1136/ bmjopen-2019-032228

- Prepublication history and additional material for this paper are available online. To view these files, please visit the journal online (http://dx.doi. org/10.1136/bmjopen-2019032228).

Received 12 June 2019 Revised 26 September 2019 Accepted 09 0ctober 2019

Check for updates

(C) Author(s) (or their employer(s)) 2019. Re-use permitted under CC BY-NC. No commercial re-use. See rights and permissions. Published by BMJ.

For numbered affiliations see end of article.

Correspondence to Mr Alem Gebremariam; alemg25@gmail.com

\section{ABSTRACT}

Objectives This study aimed to estimate the magnitude of patient and diagnostic delays and associated factors among women with breast cancer in Addis Ababa.

Design This is a cross-sectional study.

Settings and participants All women newly diagnosed with breast cancer in seven major healthcare facilities in Addis Ababa ( $n=441)$ were included in the study.

Main outcomes and measures Patient interval (time from recognition of first symptom to medical consultation) and diagnostic interval (time from first consultation to diagnosis). Patient intervals $>90$ days and diagnostic intervals $>30$ days were considered delays, and associated factors were determined using multivariable Poisson regressions with robust variance.

Results Thirty-six percent $(95 \% \mathrm{Cl}[31.1 \%, 40.3 \%])$ of the patients had patient intervals of $>90$ days, and $69 \%$ (95\% $\mathrm{Cl}[64.6 \%, 73.3 \%])$ of the patients had diagnostic intervals of $>30$ days. Diagnostic interval exceeded 1 year for $18 \%$ of patients. Ninety-five percent of the patients detected the first symptoms of breast cancer by themselves, with breast lump (78.0\%) as the most common first symptom. Only $8.0 \%$ were concerned about cancer initially, with most attributing their symptoms to other factors. In the multivariable analysis, using traditional medicine before consultation was significantly associated with increased prevalence of patient delay (adjusted prevalence ratio $(\mathrm{PR})=2.13,95 \% \mathrm{Cl}[1.68,2.71])$. First consultation at health centres (adjusted PR $=1.19,95 \% \mathrm{Cl}[1.02,1.39]$ ) and visiting $\geq 4$ facilities (adjusted $P R=1.24,95 \% \mathrm{Cl}$ $[1.10,1.40]$ ) were associated with higher prevalence of diagnostic delay. However, progression of symptoms before consultation (adjusted PR $=0.73,95 \% \mathrm{Cl}[0.60$, 0.90]) was associated with decreased prevalence of diagnostic delay.

Conclusions Patients with breast cancer in Addis Ababa have prolonged patient and diagnostic intervals. These underscore the need for public health programme to increase knowledge about breast cancer symptoms and the importance of early presentation and early diagnosis among the general public and healthcare providers.

\section{INTRODUCTION}

Breast cancer is the most commonly diagnosed cancer among women in Ethiopia, as

\section{Strengths and limitations of this study}

It is the first multicentre study on the extent of patient and diagnostic delays of breast cancer and associated factors in Ethiopia with incident breast cancer cases recruited from seven major health facilities in Addis Ababa city, representing $90 \%$ of all breast cancer cases in the city and making the findings more generalisable.

- It is also the first study to examine the extent of patient and diagnostic delays and associated factors using primary data obtained from incident cases of breast cancer.

- The retrospective nature of collecting information about dates of symptom recognition and medical consultations is prone to recall bias.

- The interviews were conducted in a hospital setting, which could have resulted in a social desirability bias leading to under-reporting of time interval before medical consultation and over-reporting of desirable behaviour such as self-breast examination.

in other parts of Africa. ${ }^{1-4}$ In Addis Ababa, the capital city of Ethiopia, breast cancer accounts for one-third of all female cancers. ${ }^{1}$ The burden of this disease is increasing in the city ${ }^{15}$ in part because of rapidly changing reproductive patterns ${ }^{6}$ : average age at first birth is rising, and the fertility rate is dropping. Similar to other areas in sub-Saharan Africa, ${ }^{7}$ a substantial proportion of patients with breast cancer in Addis Ababa are diagnosed at a late stage of the disease ${ }^{8}$ when treatment options are limited ${ }^{9}$ and the chance of survival is poor. ${ }^{811}$

The reasons for late-stage diagnosis may include prolonged patient interval (time interval in seeking medical care after recognition of symptoms) and diagnostic interval (time intervals between initial medical consultation and diagnostic confirmation). ${ }^{7} 1213$ Waiting $>3$ months before seeking care after recognition of symptoms has been associated 
with advanced-stage disease ${ }^{7}$ and poorer survival. ${ }^{14}$ Similarly, prolonged diagnostic interval has been associated with lower survival. ${ }^{15}$ Thus, understanding patients' pathways to diagnosis and the duration of these time intervals is important to developing interventions to promote earlier detection.

Only two previous studies have documented patient interval (symptom duration) of breast cancer among women in Ethiopia. ${ }^{16} 17$ One of these studies was conducted 10 years ago and was based on 69 patients diagnosed from 2003 to 2007 in a referral hospital, ${ }^{16}$ while the second study was a retrospective study based on 404 patients treated from 1 October 2005 to 30 September 2015 in one private clinic. ${ }^{17}$ Thus, the findings from these studies may not reflect the current time interval patterns in Addis Ababa or nationwide. In this analysis, we investigated time intervals experienced by women with breast cancer, from recognition of symptoms to pathological diagnosis of the disease. We also examined factors associated with patient and diagnostic intervals $>90$ days and $>30$ days, respectively. The findings from this study could inform public policy interventions aimed at decreasing stage at diagnosis and thereby improving survival.

\section{METHODS}

This paper is part of an ongoing broader project described in detail in the published protocol. ${ }^{18}$ Briefly, the methods are summarised as follows.

\section{Study design and sample size}

A cross-sectional study was conducted based on data drawn from an ongoing follow-up study in Addis Ababa. ${ }^{18}$ A baseline survey was conducted among a cohort of 441 newly diagnosed female patients with breast cancer ages $\geq 18$ years (diagnosed from 1 January 2017 to 30 June 2018) of Addis Ababa city. Taking the expected proportion $(\mathrm{p}=35.0 \%)$ of patient delay ( $>3$ months) from a similar study, ${ }^{19}$ assuming a $95 \%$ level of confidence, a $5 \%$ precision and 5\% non-response rate, a minimum of 368 patients with breast cancer were required for the study. To increase the precision of the estimates, all available newly diagnosed female patients with breast cancer aged 18 years and above enrolled in the cohort $(n=441)$ were considered in the analysis.

\section{Setting and participants}

The Ethiopian health service is structured into a threetier health system: primary healthcare level, secondary healthcare level and tertiary healthcare level connected to each other by a referral system. The primary healthcare service points for urban settings like Addis Ababa include health centres, private clinics and primary hospitals, while secondary and tertiary healthcare levels are composed of general hospitals and specialised hospitals, respectively. Compared with hospitals, health centres are more likely to be staffed by nurses and health officers (graduate of a 4-year training programme in biomedical, clinical and public health courses), and they mainly provide preventive and primary care ${ }^{20}$ Specific to breast cancer, health centre staff are expected to create community awareness on the availability and importance of clinical breast examination services, and refer women suspected of breast cancer to general hospitals for diagnostic services. ${ }^{21}$

The study participants were recruited sequentially from seven public and private health facilities (Tikur Anbessa Specialised Hospital, St. Paul Hospital Millennium Medical College, Betezata Hospital, Hallelujah General Hospital, Landmark Hospital, Legehar Hospital and United Vision Medical Services Centre) in Addis Ababa city. These health facilities capture more than $90 \%$ of all women with breast cancer reported to the cancer registry in Addis Ababa. Recruitment of the study participants began on 20 March 2017 and ended on 31 July 2018.

On daily basis, the research assistant assigned in each of the selected seven health facilities identified eligible women while they were waiting to be seen by their physician by examining the medical chart for their place of residence and their pathology reports for the date of diagnosis. To avoid duplication, the medical chart of the recruited woman was coded on its top cover and plastered with yellow. Concurrently, the monthly report of the Addis Ababa cancer registry cancer notification form was assessed to identify eligible women who were not captured in the seven health facilities. These women were contacted by phone for their place of follow-up and convenient date and time to meet for our interview. Of the 444 patients approached, 441 (99.3\%) provided informed consent to participate in the study.

Prior to the interview, study participants were informed about the purpose of the study and their right to refuse to participate or withdraw at any point during the study period. Then verbal consent was obtained from the study participants using Amharic, the national working language. The decision to use verbal consent was informed by a rapid ethical assessment we conducted to design the consent process of this project. ${ }^{22}$ Based on this assessment, we found that most of the participants were not comfortable providing written consent.

\section{Variables and measurements}

We used the Aarhus statement criteria ${ }^{23}$ for classifying patient and diagnostic intervals. Accordingly, patient interval was defined as the interval from the date of first recognition of symptoms (the time point when first bodily changes and/or symptoms are noticed) to the date of first clinical presentation (the date at which the patient first presented to a healthcare provider after first recognition of symptoms) ${ }^{23}$ Those patients in whom breast abnormalities were first identified by physicians or mammography were excluded from our computation of patient interval $(\mathrm{n}=24)$.

Diagnostic interval was defined as the interval from the date of first clinical presentation to the date of pathological diagnosis (the date at which the first histological or cytological confirmation of this malignancy was 
documented in the pathology report). ${ }^{23}$ The date of diagnosis was taken from the patient's pathology report.

Information on time intervals and other information related to diagnosis of breast cancer was collected using a questionnaire adapted with modification from a similar study conducted in Rwanda. ${ }^{24}$ Before being executed, the questionnaire was pretested for its cultural appropriateness and clarity. Trained nurses interviewed the eligible women individually in a semiprivate room in Amharic, when they presented for treatment. To minimise recall bias, only newly diagnosed patients were included in the study. The median length of time (IQR) between pathological diagnosis and interview was $30(10-73.5)$ days. If the participants were unable to recall the exact date of first symptom recognition, they were asked to provide a month or year ("was it at the beginning, middle, or end of the year?'). For those who remembered only the month $(n=232)$, the date was estimated as the 15 th day of that month. If the participants only said the beginning, middle or end of the year $(n=61)$, the estimated date was 15th of February, June or October of the year, respectively; for those who were only able to provide the year $(n=44)$, the estimated date was June 30th of that year. Similarly, for those who could remember only the month $(n=206)$ of first clinical presentation, the date was estimated as the 15th day of that month. If they only remembered the beginning, middle or end of the year $(n=34)$, the estimated date was 15th of February, June or October of the year, respectively. For those who were only able to recall the year $(n=25)$, the estimated date was June 30th of that year. ${ }^{24}$ We performed sensitivity analyses excluding patients who had only remembered the beginning, middle or end of the year or a year for the date of first symptom recognition or clinical presentation (online supplementary table 1 ).

\section{Data analysis}

Data were analysed using Stata V.14. We computed descriptive statistics for each of the study variables. Categorical variables are presented as numbers and percentages. For numerical variables, we present means with their SD for those with normal distribution, and median and IQR for those variables with skewed distributions.

Similar to previous studies, patient ${ }^{24-27}$ and diagnostic $^{19} 2829$ delays were defined as >90-day patient interval and >30-day diagnostic interval, respectively. In cross-sectional studies, logistic regression is frequently used to estimate an OR as an association measure equivalent to the relative risk (RR). However, when the proportion experiencing an outcome exceeds $10 \%$, an OR overestimates the RR and makes its interpretation unintuitive, and the prevalence ratio (PR) is a more accurate measure of association. ${ }^{30} 31$ Thus, Poisson regression with robust variance was used to compute the adjusted PRs of the factors associated with the presence of patient and diagnostic delays. Variables reported in the literature as having an impact on patient and diagnostic delays, and those variables found to be associated ( $p$ value $<0.25$ ) with $>90$-day patient interval or >30-day diagnostic interval on univariable analysis were selected for the multivariable analysis model. The cut-off for $p$ value at 0.25 for variable selection to multivariable analysis is supported by various literature. ${ }^{32}{ }^{33}$ Due to the lower sample size the variables had, woman's partner education $(n=241)$ and woman's number of alive children $(n=336)$ were not included in the multivariable regression model. Statistical significance was declared as having a two-sided $\mathrm{p}$ value of $<0.05$.

\section{Patient and public involvement}

Neither patients nor the public were involved in the planning or design of the study. However, we conducted a rapid ethical assessment among women with breast and cervical cancer, family members and healthcare providers for designing consent of study participants. ${ }^{22}$

\section{RESULTS}

Table 1 shows the sociodemographic characteristics of the 441 study participants. The mean (SD) age of the participants was 44.4 (12.2) years. Forty-five percent of the participants did not attend school or had only primarylevel education. Seventy-four percent of the participants reported family income of less than US $\$ 194$ per month; and $71 \%$ of the participants paid their medical expenses out of pocket.

One-third of participants $(32.2 \%, 95 \%$ CI [27.9\%, $36.6 \%]$ ) had never heard of breast cancer, $73 \%$ of the study participants did not know how to do a breast selfexamination and 9 in 10 patients had no history of clinical or mammographic breast examination before they noticed the first symptom of their illness.

A breast lump (78.0\%) was the most common symptom recognised first, followed by pain $(10.2 \%)$, change in colour of the nipple $(4.8 \%)$ and breast discharge $(4.3 \%)$. For $95 \%$ of the participants, the first symptom was selfdetected. Among the self-detected participants, only $8.0 \%$ considered the first symptoms as possible symptoms of cancer, while $36 \%$ considered it as a simple breast swelling and $56.0 \%$ attributed to others (eg, sun stroke, cold exposure, menses, breast milk). Thirteen percent of the participants used traditional medicines such as holy water and visiting traditional healers before seeking medical consultation. Notably, $19 \%$ of the participants waited until they recognised progression of their breast cancer symptom(s).

The main triggers for seeking medical care were the first breast cancer symptoms $(70.0 \%)$, followed by noticing progression of symptoms $(14.1 \%)$ and persuasion from family members/friends $(13.2 \%)$. Thirty-six percent of patients first had their symptoms assessed at a health centre, $40.5 \%$ at private hospital/clinic and $23.3 \%$ at public hospital. About a quarter of patients visited $\geq 4$ different healthcare facilities (maximum 12 facilities), and $23 \%$ of the patients made $\geq 10$ visits to healthcare facilities (maximum 21 visits) before final pathological diagnosis of their disease. 
Table 1 Sociodemographic characteristics of women with breast cancer diagnosed from 2017 to 2018, Addis Ababa, Ethiopia $(n=441)$

\begin{tabular}{lcc}
\hline $\begin{array}{l}\text { Sociodemographic } \\
\text { characteristics }\end{array}$ & Frequency & Percentage \\
\hline $\begin{array}{l}\text { Age at diagnosis (years) } \\
\text { <30 }\end{array}$ & 40 & 9.1 \\
$30-39$ & 145 & 32.9 \\
$40-49$ & 106 & 24 \\
\hline $50-59$ & 82 & 18.6 \\
$60-69$ & 54 & 12.2 \\
\hline$>=70$ & 14 & 3.2 \\
\hline
\end{tabular}

Highest level of education

\begin{tabular}{|c|c|c|}
\hline Not attended school & 87 & 19.7 \\
\hline Primary school (1st-8th) & 112 & 25.4 \\
\hline Secondary school (9th-12th) & 142 & 32.2 \\
\hline Diploma and above & 100 & 22.7 \\
\hline \multicolumn{3}{|l|}{ Marital status } \\
\hline Married & 255 & 57.8 \\
\hline Widowed & 73 & 16.6 \\
\hline Single & 67 & 15.2 \\
\hline Divorced & 46 & 10.4 \\
\hline \multicolumn{3}{|l|}{ Occupation } \\
\hline Housewife (homemaker) & 217 & 49.2 \\
\hline Employed outside the home & 198 & 44.9 \\
\hline Retired & 13 & 2.9 \\
\hline No job & 13 & 2.9 \\
\hline \multicolumn{3}{|l|}{ Family size } \\
\hline$<=2$ & 65 & 14.7 \\
\hline $3-5$ & 260 & 59 \\
\hline$>6$ & 116 & 26.3 \\
\hline \multicolumn{3}{|l|}{ Family monthly income (US\$*) } \\
\hline$<61.0$ & 125 & 28.3 \\
\hline $61.0-194.0$ & 200 & 45.4 \\
\hline $194.0-403.0$ & 81 & 18.4 \\
\hline$>403.0$ & 25 & 5.7 \\
\hline Unknown & 7 & 1.6 \\
\hline No income & 3 & 0.7 \\
\hline \multicolumn{3}{|l|}{ Source of medical expenses } \\
\hline Out of pocket & 313 & 71 \\
\hline Free medical care & 103 & 23.4 \\
\hline Health insurance & 25 & 5.6 \\
\hline
\end{tabular}

${ }^{*} \mathrm{ETB}=\mathrm{US} \$ 0.037$.

\section{Patient intervals}

The median (IQR) patient interval was 30 (6-132) days. More than a third $(35.7 \%, 95 \%$ CI $[31.1 \%, 40.3 \%])$ of the patients waited for longer than 3 months before seeking medical care, and $11 \%$ of the patients waited for over a year (online supplementary table 1 ). When patients who waited $>3$ months to seek medical care were asked their main reasons, $69 \%$ of them said "not bothered by the problem at first," followed by using holy water/visiting traditional healers first $(17.4 \%)$, and unable to take time off from work (12.7\%) (online supplementary table 2).

\section{Diagnostic intervals}

The median (IQR) diagnostic interval was 69 (22-213) days. More than two-thirds $(69.1 \%, 95 \%$ CI [64.6\%, $73.3 \%]$ ) of the patients waited for longer than a month and $18 \%$ of the patients waited more than a year to receive diagnostic confirmation after their initial medical presentation (online supplementary table 1 ). The most common reasons given by the patients for extended diagnostic delays (over a year) include both provider factors such as misdiagnosis (25.6\%), false-negative laboratory results $(3.8 \%)$ and lack of empathy at first medical consultation $(3.8 \%)$, and patient factors such as use of traditional medicine $(20.5 \%)$, fear of cancer diagnosis and treatment (especially breast surgery) (17.7\%), lack of awareness about disease severity (6.4\%), and financial barriers for diagnosis and treatment (3.8\%) (online supplementary table 2). By type of health facilities visited for first medical consultation, the median diagnostic interval ranged from 89 days among patients who visited health centres to 55 days among those patients who visited public hospitals. The median number of visits to healthcare facilities before diagnostic confirmation varied from eight visits among patients who visited health centres to four visits among those who visited public or private hospitals/clinics.

\section{Factors associated with patient and diagnostic delays}

In unadjusted analysis, women's age $\geq 60$ years ( $P R=1.47$, $\mathrm{p}=0.030)$, women who did not attend school $(\mathrm{PR}=2.19$, $\mathrm{p}=0.000)$ or complete secondary school $(\mathrm{PR}=1.63$, $\mathrm{p}=0.025)$, having partner who did not attend school $(\mathrm{PR}=2.04, \mathrm{p}=0.006)$, having $\geq 5$ children $(\mathrm{PR}=1.61$, $p=0.009)$, never having heard of breast cancer before symptom recognition $(\mathrm{PR}=1.34, \mathrm{p}=0.024)$ and using traditional medicine before consultation $(\mathrm{PR}=2.31, \mathrm{p}$ $=0.000)$ were significantly associated with higher prevalence of patient delay. After adjustment, using traditional medicine before consultation (adjusted PR $=2.13$, 95 CI\% $[1.68,2.71])$ was the only factor significantly associated with increased prevalence of patient delay (online supplementary table 3 ).

After adjustment for the participants' sociodemographic variables, having first consultation at a health centre (adjusted PR $=1.19,95 \%$ CI $[1.02,1.39]$ ) and visits to $\geq 4$ health facilities before confirmation (adjusted PR $=1.24,95 \%$ CI $[1.10,1.40]$ ) were significantly associated with increased prevalence of diagnostic delay. In contrast, consultation after recognition of symptom progression (adjusted PR $=0.73,95 \%$ CI $[0.60,0.90]$ ) was associated with lower prevalence of diagnostic delay (online supplemental table 3). 


\section{DISCUSSION}

We found that women with breast cancer in Addis Ababa have prolonged patient and diagnostic intervals, with one-third of the patients waiting for $>3$ months before seeking medical care, and nearly one-fifth of the patients waiting over a year before receiving diagnostic confirmation. In addition, about a quarter of patients visited $\geq 4$ different healthcare facilities, and a quarter of the patients made $\geq 10$ visits to healthcare facilities before diagnostic confirmation.

In our cohort, the proportion of patient delay was substantially lower than those found in two single institution-based studies in Addis Ababa. ${ }^{16} 17$ These differences may reflect differences in the study participants' residence and improvement in patients' awareness over the last 13 years (2003-2015) since the previous studies were conducted. About one-third of the patients in the single-institution based studies ${ }^{16} 17$ resided outside of Addis Ababa, and patients residing outside the city have been reported to have less knowledge about breast cancer and less access to healthcare services. ${ }^{6}$

Similarly, compared with studies in sub-Saharan African countries, the median patient interval in our study (30 days) was considerably shorter than those reported from Rwanda (150 days) ${ }^{24}$ and Mali (144 days), ${ }^{34}$ but comparable with that reported from South Africa (23 days). ${ }^{35}$ As expected, compared with findings from countries outside of sub-Saharan Africa, however, our finding of median patient interval is generally longer. ${ }^{36} 37$

Knowledge on the risk of breast cancer, screening and other early detection methods, initial symptoms, and its treatment is important for appraisal of first symptoms and for seeking timely medical care. ${ }^{38-40}$ However, a third of the women with breast cancer in our study had never previously heard of breast cancer. Only $8 \%$ of the patients suspected their first symptom to be a symptom of breast cancer. A substantial proportion of patients either disregarded the clinical importance of the first symptoms or attributed them to other nonspecific conditions. Sharp et al identified 'knowledge deficit a modifiable factor' as a main barrier to early detection of breast cancer in Uganda. ${ }^{12}$ In addition to the patients, our findings suggest the presence of providers' oversight of initial breast cancer symptoms leading to delayed referral of the patients for confirmation. These findings underscore the need for programme to enhance knowledge about breast cancer symptoms among the general public and healthcare providers. $^{41} 42$

Birhan et al reported that cancer patients were among the most common visitors to traditional healers in Addis Ababa. ${ }^{43}$ Thirteen percent of our study participants' immediate response to the first breast cancer symptoms was using traditional medicines, which was significantly associated with increased prevalence of patient delay. This practice has been shown to affect patients' decision to seek timely medical care ${ }^{35} 38$ and to prolong patient interval in Ethiopia ${ }^{161744}$ and other parts of Africa. ${ }^{24} 3445$ This is partly due to the belief that cancer is fatal and incurable by conventional medical treatment. ${ }^{44} 46$
Our finding of median diagnostic interval (69 days) was lower than that reported in Rwanda (150 days) ${ }^{24}$ but longer than those reported in Mali (27 days) ${ }^{34}$ and South Africa (28 days). ${ }^{35}$ Sixty-nine percent of the patients in our study waited for $>30$ days, and $18 \%$ for over a year to receive diagnostic confirmation following first medical consultation for their disease. Provider factors that may have contributed to this considerably prolonged diagnostic interval, as reported by the patients, include difficulties of navigating the healthcare system, misdiagnosis of clinical manifestations and false-negative laboratory results. Although our study has not explicitly estimated the pathology result turnaround times, some portion of the diagnosis delays we observed could be attributed to prolonged pathology result turnaround times in the few available diagnostic facilities in the city. Similar to other sub-Saharan countries, ${ }^{47}$ patients with cancer in Addis Ababa waited on average for 15 days to get the pathology result. ${ }^{9}$

In the multivariable analysis, diagnostic delay was associated with first consultation at a health centre, and visits to $\geq 4$ healthcare facilities before diagnosis confirmation. On average, patients visited at least three different healthcare facilities and made about seven visits before receiving diagnostic confirmation. The number of visits was substantially higher among those patients whose first consultation was at a health centre, in part because of the additional time needed for referring patients to hospitals. $^{20}$ This may also reflect a low level of breast cancer knowledge among both providers and patients in the health centres, as health centre providers are more likely to be nurses or health officers than doctors, and patients visiting health centres are more likely to be less educated compared with those visiting private clinics or hospitals. A study conducted among female nurses ${ }^{48}$ in Addis Ababa found poor general knowledge about breast cancer.

In contrast, patients who sought medical consultation after progression of symptom(s) had lower prevalence of diagnostic delay. This is likely because more extensive breast symptoms or signs may have led to prompt referral of patients to diagnostic centres as reported elsewhere. ${ }^{4950}$ Similar to other literature ${ }^{51-53}$ patient-related factors such as belief in traditional medicine, fear of cancer diagnosis and treatment, refusal of breast removal, and time and financial barriers were also reported as influencing the diagnostic interval.

There are no breast cancer screening services in Addis Ababa or other parts of Ethiopia. Therefore, early diagnosis is dependent on patients' decision to seek care after initial recognition of symptoms, and healthcare providers' timely evaluation and referral for confirmation. This study was conducted in the capital city, Addis Ababa, where the population has better access to health information and service compared with the rest of Ethiopia. ${ }^{6}$ A substantial number of women with breast cancer in the city experienced prolonged patient and diagnostic intervals due to both individual and health system-related factors. Provider delay is more common than patient delay. This may in part reflect lack of referrals to a specialised centre for a substantial 
proportion of patients with suggestive signs and symptoms of breast cancer, which in turn calls for training of front-line health workers to improve their clinical suspicion skills and early referral. Moreover, strengthening the referral linkage between the health centres and the hospitals could increase early detection of breast cancer.

To our knowledge, this study is the first multicentre study on extent of patient and diagnostic delays of breast cancer and associated factors in Ethiopia with incident cases recruited from seven major health facilities in Addis Ababa, representing about $90 \%$ of all incident breast cancer cases in the city. However, our study has limitations. First, information about the dates of symptom recognition and medical consultations was dependent on the participants' memory and therefore may not be free of recall bias. However, we have attempted to mitigate recall bias by restricting our study participants to those newly diagnosed cases and using local events to recall the date of first symptom recognition and presentation. We additionally performed a sensitivity analysis and found no statistically significant difference in the association results (adjusted PRs) and the proportions of women across the different cut-points of time intervals, except for those who waited for less than a month and more than a year before consultation. This may be because patients who waited on consultation for more than a year are less likely to remember the date of first symptom recognition than those who consulted within a year of their symptom recognition. Inclusion of these patients in the analysis pooled the estimates across the different cut-points of time intervals ( $\leq 30$ days, $31-90$ days, $91-180$ days, $180-365$ days and $>365$ days) towards the highest waiting interval (>365 days), while exclusion of these patients from the analysis pooled the estimates towards the lowest waiting interval ( $\leq 30$ days). Thus, we would not expect our estimation strategy to bias our results in a particular direction. Second, the date of diagnosis was taken from the pathology report; however, this may not reflect when the patient received the diagnosis. Third, the interviews were conducted in a hospital setting, which could have resulted in a social desirability bias leading to under-reporting of patient and diagnostic delays and overreporting of desirable behaviour such as self-breast examination. Fourth, it is possible that the long waiting period for some of the cases may reflect indolent breast cancer cases ${ }^{54}$ or benign breast conditions. Fifth, the study was a hospitalbased study, and thus might not capture the experience of women who solely seek care elsewhere (eg, traditional or spiritual healers) or women who are seen only at primary care facilities and do not get to the hospital. Lastly, our study may be underpowered to detect a significant association for some of the independent variables.

\section{CONCLUSIONS}

In this multicentre study, we have found that substantial proportions of women with breast cancer in Addis Ababa have prolonged patient and diagnostic intervals attributed to modifiable patient and healthcare provider factors such as poor knowledge about breast cancer, downplaying the importance of the first breast cancer symptoms, preference of traditional and spiritual remedies, provider's oversight of the first symptoms and delayed referral of women for confirmation with suggestive of breast cancer symptoms. These underscore the need for public health programme to increase knowledge about breast cancer among the general population and healthcare providers in the city in order to reduce the morbidity and mortality associated with the disease.

\section{Author affiliations}

${ }^{1}$ Public Health, Adigrat University College of Medicine and Health Sciences, Adigrat, Ethiopia

${ }^{2}$ Preventive Medicine, Addis Ababa University School of Public Health, Addis Ababa, Ethiopia

${ }^{3}$ Radiotherapy Center, Addis Ababa University School of Medicine, Addis Ababa,

Ethiopia

${ }^{4}$ Medicine, Brigham and Women's Hospital, Boston, Massachuset, USA

${ }^{5}$ Institute for Medical Epidemiology, Biostatistics and Informatics, Martin-Luther-

University Halle-Wittenberg, Halle, Germany

${ }^{6}$ Surveillance and Health Services Research, American Cancer Society, Atlanta, Georgia, USA

Acknowledgements We would like to thank all members of the participating healthcare facilities for their cooperation and support in arranging the eligible study participants. Also, we thank the data collectors and study participants for their time and cooperation. Finally, we thank Mr. John M. Daniel of the American Cancer Society for editing the manuscript.

Contributors AG, AA, AW, MA and AJ conceptualise the study. AG analysed and wrote the first draft of the manuscript. AA, AW, MA, EJK, LEP and AJ commented on the designing of the study and reviewed the final draft of the manuscript. All authors read and approved the final draft of the manuscript.

Funding This work was supported by the Intramural Research Department of the American Cancer Society.

Disclaimer The funder has no role in the study design; in the collection, analysis and interpretation of the data; in the writing of the report; and in the decision to submit the paper for publication.

Competing interests None declared.

Patient consent for publication Not required.

Ethics approval We had obtained verbal consent from the study participants which was approved by the Institutional Review Board (018/17/SPH) of the College of Health Science of Addis Ababa University.

Provenance and peer review Not commissioned; externally peer reviewed. Data availability statement Data are available on reasonable request.

Open access This is an open access article distributed in accordance with the Creative Commons Attribution Non Commercial (CC BY-NC 4.0) license, which permits others to distribute, remix, adapt, build upon this work non-commercially, and license their derivative works on different terms, provided the original work is properly cited, appropriate credit is given, any changes made indicated, and the use is non-commercial. See: http://creativecommons.org/licenses/by-nc/4.0/.

\section{ORCID iDs}

Alem Gebremariam http://orcid.org/0000-0003-2173-6685

Eva Johanna Kantelhardt http://orcid.org/0000-0001-7935-719X

\section{REFERENCES}

1 Timotewos G, Solomon A, Mathewos A, et al. First data from a population based cancer registry in Ethiopia. Cancer Epidemio 2018;53:93-8.

2 Abebe $\mathrm{E}$, Abebe H. Types of cancers diagnosed and the preference of families of adult patients with cancer about disclosing diagnosis to the patients. Ethiop J Health Sci 2017;27:255-62.

3 Kantelhardt EJ, Muluken G, Sefonias G, et al. A review on breast cancer care in Africa. Breast Care 2015;10:364-70. 
4 Darre T, Kpatcha TM, Bagny A, et al. Descriptive epidemiology of cancers in Togo from 2009 to 2016. Asian Pac J Cancer Prev 2017;18:3407-11.

5 Abate SM, Yilma Z, Assefa M, et al. Trends of breast cancer in Ethiopia. Int J Cancer Res Mol Mech 2016;2.

6 Central Statistical Agency (CSA) [Ethiopia] and ICF. Ethiopia demographic and health survey 2016. Addis Ababa, Ethiopia, and Rockville, Maryland, USA: CSA and ICF, 2016.

7 McKenzie F, Zietsman A, Galukande M, et al. Drivers of advanced stage at breast cancer diagnosis in the multicountry African breast cancer - disparities in outcomes (ABC-DO) study. Int $J$ Cancer 2018;142:1568-79.

8 Kantelhardt EJ, Zerche P, Mathewos A, et al. Breast cancer survival in Ethiopia: a cohort study of 1,070 women. Int $J$ Cancer 2014:135:702-9.

9 Haileselassie W, Kaba M, Sellasie MA, et al. Challenges and opportunities in cancer diagnosis in Ethiopia: In-depth exploration of practitioners' view. Int J Curr Res 2017;9:54662-8.

10 Addissie A, Braun G, Demeke T, et al. Breast health global initiative recommended breast cancer prevention and care in rural Ethiopia. $J$ Glob Oncol 2018;4:1s-s.

11 Eber-Schulz P, Tariku W, Reibold C, et al. Survival of breast cancer patients in rural Ethiopia. Breast Cancer Res Treat 2018;170:111-8.

12 Sharp JW, Hippe DS, Nakigudde G, et al. Modifiable patient-related barriers and their association with breast cancer detection practices among Ugandan women without a diagnosis of breast cancer. PLOS One 2019;14:13

13 Dye TD, Bogale S, Hobden C, et al. Complex care systems in developing countries: breast cancer patient navigation in Ethiopia. Cancer 2010;116:577-85.

14 Richards MA, Westcombe AM, Love SB, et al. Influence of delay on survival in patients with breast cancer: a systematic review. Lancet 1999;353:1119-26.

15 Ángeles-Llerenas A, Torres-Mejía G, Lazcano-Ponce E, et al. Effect of care-delivery delay on the survival of Mexican women with breast cancer. Salud Pública de México 2016;58:237-50.

16 Dye TD, Bogale S, Hobden C, et al. Experience of initial symptoms of breast cancer and triggers for action in Ethiopia. Int $J$ Breast Cancer 2012;2012:1-5.

17 Ersumo T, Tamrat G, Solomon B, et al. Breast cancer in a private medical services center: a 10 year experiance. Ethiop Med $J$ 2018;56.

18 Gebremariam A, Addissie A, Worku A, et al. Breast and cervical cancer patients' experience in Addis Ababa city, Ethiopia: a follow-up study protocol. BMJ Open 2019:9:e027034.

19 Mohd Mujar NM, Dahlui M, Emran NA, et al. Complementary and alternative medicine (cam) use and delays in presentation and diagnosis of breast cancer patients in public hospitals in Malaysia. PLoS One 2017;12:e0176394

20 Federal Democratic Republic of Ethiopia Ministry of Health Medical Services Directorate. Guidline for implementation of patient referal system, 2010. Available: https://www.medbox.org/ethiopia-guidelinefor-implementation-of-a-patient-referral-system/download.pdf [Accessed 3 Dec 2018].

21 Federal Ministry of Health Ethiopia Disease Prevention and Control Directorate. National cancer control plan 2016-2020, 2015 Available: https://www.iccp-portal.org/sites/default/files/plans/ NCCP\%20Ethiopia\%20Final\%20261015.pdf [Accessed 22 Feb 2019].

22 Gebremariam A, Yalew AW, Hirpa S, et al. Application of the rapid ethical assessment approach to enhance the ethical conduct of longitudinal population based female cancer research in an urban setting in Ethiopia. BMC Med Ethics 2018;19:87.

23 Weller D, Vedsted P, Rubin G, et al. The Aarhus statement: improving design and reporting of studies on early cancer diagnosis. $\mathrm{Br} \mathrm{J}$ Cancer 2012;106:1262-7.

24 Pace LE, Mpunga T, Hategekimana V, et al. Delays in breast cancer presentation and diagnosis at two rural cancer referral centers in Rwanda. Oncologist 2015;20:780-8.

25 Sharma K, Costas A, Damuse R, et al. The Haiti breast cancer initiative: initial findings and analysis of barriers-to-care delaying patient presentation. Hindawi Publishing Corporation, 2013.

26 Ramirez AJ, Westcombe AM, Burgess CC, et al. Factors predicting delayed presentation of symptomatic breast cancer: a systematic review. Lancet 1999;353:1127-31.

27 Sharma K, Costas A, Shulman LN, et al. A systematic review of barriers to breast cancer care in developing countries resulting in delayed patient presentation. J Oncol 2012;2012:8.

28 Huo Q, Cai C, Zhang Y, et al. Delay in diagnosis and treatment of symptomatic breast cancer in China. Ann Surg Oncol 2015;22:883-8.
29 Elmore JG, Nakano CY, Linden HM, et al. Racial inequities in the timing of breast cancer detection, diagnosis, and initiation of treatment. Med Care 2005;43:141-8.

30 Martinez BAF, Leotti VB, Silva GdeSe, et al. Odds ratio or prevalence ratio? an overview of reported statistical methods and appropriateness of interpretations in cross-sectional studies with dichotomous outcomes in veterinary medicine. Front Vet Sci 2017;4.

31 Tamhane AR, Westfall AO, Burkholder GA, et al. Prevalence odds ratio versus prevalence ratio: choice comes with consequences. Stat Med 2017;36:3760.

32 Bursac Z, Gauss CH, Williams DK, et al. Purposeful selection of variables in logistic regression. Source Code Biol Med 2008;3:8.

33 Norsa'adah B, Rampal KG, Rahmah MA, et al. Diagnosis delay of breast cancer and its associated factors in Malaysian women. BMC Cancer 2011:11:141.

34 Grosse Frie K, Kamaté B, Traoré CB, et al. Factors associated with time to first healthcare visit, diagnosis and treatment, and their impact on survival among breast cancer patients in Mali. PLoS One 2018;13:e0207928.

35 Moodley J, Cairncross L, Naiker T, et al. From symptom discovery to treatment - women's pathways to breast cancer care: a crosssectional study. BMC Cancer 2018;18:312.

36 Stamatovic L, Vasovic S, Trifunovic J, et al. Factors influencing time to seeking medical advice and onset of treatment in women who are diagnosed with breast cancer in Serbia. Psychooncology 2018;27:576-82

37 Poum A, Promthet S, Duffy SW, et al. Factors associated with delayed diagnosis of breast cancer in northeast Thailand. $J$ Epidemiol 2014;24:102-8.

38 Unger-Saldaña K, Infante-Castañeda CB. Breast cancer delay: a grounded model of help-seeking behaviour. Soc Sci Med 2011;72:1096-104.

39 Bodapati SL, Babu GR. Oncologist perspectives on breast cancer screening in India-Results from a qualitative study in Andhra Pradesh. Asian Pac J Cancer Prev 2013;14:5817-23.

40 Webber C, Jiang L, Grunfeld E, et al. Identifying predictors of delayed diagnoses in symptomatic breast cancer: a scoping review. Eur $J$ Cancer Care 2017;26:e12483.

41 Odongo J, Makumbi T, Kalungi S, et al. Patient delay factors in women presenting with breast cancer in a low income country. BMC Res Notes 2015;8:467.

42 Gadgil A, Sauvaget C, Roy N, et al. Cancer early detection program based on awareness and clinical breast examination: interim results from an urban community in Mumbai, India. Breast 2017;31:85-9.

43 Birhan W, Giday M, Teklehaymanot T. The contribution of traditional healers' clinics to public health care system in Addis Ababa, Ethiopia: a cross-sectional study. J Ethnobiol Ethnomed 2011;7:39.

44 Gebremariam A, Addissie A, Worku A, et al. Perspectives of patients, family members, and health care providers on late diagnosis of breast cancer in Ethiopia: a qualitative study. PLoS One 2019;14:e0220769.

45 Akuoko CP, Armah E, Sarpong T, et al. Barriers to early presentation and diagnosis of breast cancer among African women living in subSaharan Africa. PLoS One 2017;12:e0171024.

46 Haileselassie W, Mulugeta T, Tigeneh W, et al. The situation of cancer treatment in Ethiopia: challenges and opportunities. J Cancer Prev 2019;24:33-42.

47 Martei YM, Narasimhamurthy M, Prabhakar P, et al. Breast cancer pathology turnaround time in Botswana. $J$ Glob Oncol 2018;4:1-7.

48 Lemlem SB, Sinishaw W, Hailu M, et al. Assessment of knowledge of breast cancer and screening methods among nurses in university hospitals in Addis Ababa, Ethiopia, 2011. ISRN Oncol 2013;2013:1-8.

49 Tjemsland L, Søreide JA. Operable breast cancer patients with diagnostic delay--oncological and emotional characteristics. Eur J Surg Oncol 2004;30:721-7.

50 Dang-Tan T, Franco EL. Diagnosis delays in childhood cancer. Cancer 2007:110:703-13.

51 Yusoff N, Taib NAM, Ahmad A. The health seeking trajectories of Malaysian women and their husbands in delay cases of breast cancer: a qualitative study. Asian Pac J Cancer Prev 2011;12:2563-70.

52 Abu-Helalah AM, Alshraideh HA, Al-Hanaqtah Mo'tasem, et al. Delay in presentation, diagnosis, and treatment for breast cancer patients in Jordan. Breast $J$ 2016;22:213-7.

53 Khakbazan Z, Roudsari RL, Taghipour A, et al. Appraisal of breast cancer symptoms by Iranian women: entangled cognitive, emotional and socio-cultural responses. Asian Pac J Cancer Prev 2014:15:8135-42.

54 Delahaye LJMJ, Drukker CA, Dreezen C, et al. A breast cancer gene signature for indolent disease. Breast Cancer Res Treat 2017; $164: 461-6$ 